\title{
Peritonitis bacteriana espontánea en un paciente anciano ex alcohólico
}

\author{
Cristóbal del Rosario-Quintana ${ }^{a}$, Carmelo Monzón-Moreno y Mar Ojeda-Vargasa ${ }^{\mathrm{a}, \mathrm{b}}$

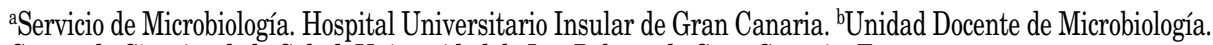 \\ Centro de Ciencias de la Salud. Universidad de Las Palmas de Gran Canaria. España.
}

\section{Caso clínico}

Varón de 80 años de edad, ex alcohólico crónico, con adenocarcinoma de próstata en tratamiento con antiandrógenos. Vive en una residencia de ancianos, no presenta deterioro cognitivo y necesita ayuda para las actividades básicas de la vida diaria, sin control de esfínteres.

Fue traído al hospital por un cuadro de $24 \mathrm{~h}$ de evolución de coloración amarillenta de piel y mucosas con orina oscura y deposiciones blanquecinas. Una semana antes del ingreso, presentó un cuadro autolimitado de vómitos y diarreas.

A la exploración, presentaba febrícula, moderada deshidratación, ictericia mucocutánea, abdomen globuloso, no doloroso, donde se palpaba hepatomegalia dura. No había signos de irritación peritoneal. Las analíticas mostraban una anemia normocítica y serologías de virus de hepatitis B y C negativas.

A la semana del ingreso, el paciente presentaba ascitis y se procedió a una paracentesis diagnóstica, que mostró un líquido ascítico con 2.400 leucocitos/ $\mu$ l, $84 \%$ de polimorfonucleares, una lactato deshidrogenasa (LDH) de 181 U/1 y una anatomía patológica negativa para malignidad. Se envió el líquido ascítico en frascos de hemocultivos para análisis microbiológico y se instauró tratamiento antibiótico empírico con cefotaxima (2 g/8 h i.v.).

\section{Diagnóstico y evolución}

A pesar del tratamiento, en controles posteriores no se objetivó una respuesta clínica satisfactoria por lo que, tras consultar con el laboratorio de microbiología, se cambió la cefotaxima por imipenem $(500 \mathrm{mg} / 6 \mathrm{~h}$ i.v.), con mejora sustancial y resolución posterior del cuadro.

Como resultado del cultivo, se obtuvo un crecimiento en medios generales (tanto en atmósfera aerobia como anaerobia, siendo el crecimiento igual de abundante en ambos casos) de colonias planas blanco-grisáceas, no hemolíticas (fig. 1), catalasa negativas, que se teñían al Gram como bacilos grampositivos (en anaerobiosis) y Gram variables (en aerobiosis). En anaerobiosis se produjo la formación de esporas terminales (fig. 2). La identificación, llevada a cabo con la galería API 20 A (BioMérieux) incubada en anaerobiosis a $37^{\circ} \mathrm{C}$ durante $48 \mathrm{~h}$, dio como resultado Clostridium tertium (excelente identificación). El antibiograma

Correspondencia: Dr. C. Monzón-Moreno.

Apartado de correos 550. 35080 Las Palmas de Gran Canaria. España.

Correo electrónico: cmonzon@dcc.ulpgc.es

Manuscrito recibido el 19-7-2005; aceptado el 2-11-2005.

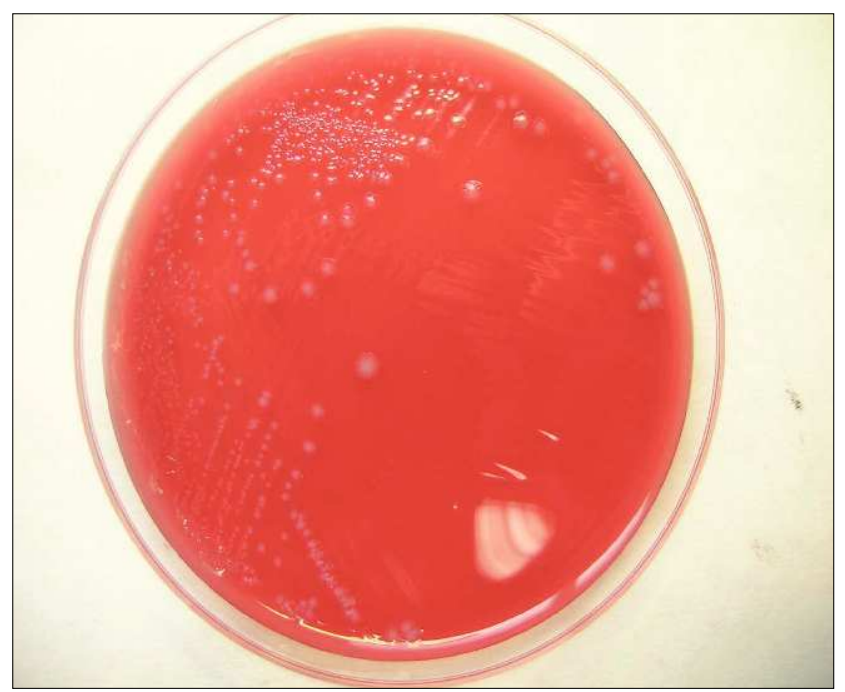

Figura 1. Cultivo en Brucella Agar.

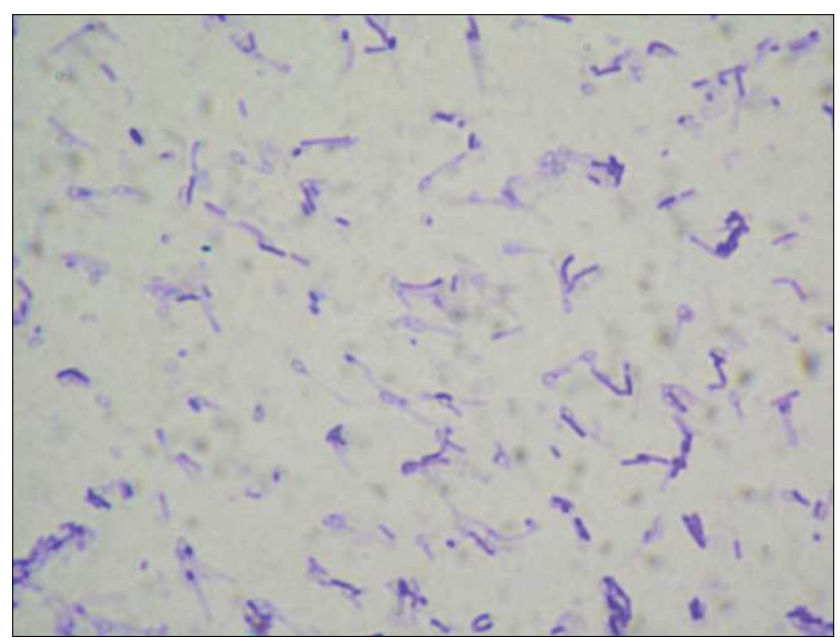

Figura 2. Gram de una colonia. (x1.000.)

(método Etest ${ }^{\circledR}, \mathrm{AB}$ BIODISK) mostró que la cepa era sensible in vitro a penicilina, amoxicilina/ácido clavulánico, cefoxitina, cefotaxima, piperacilina/tazobactam, imipenem y metronidazol, siendo resistente a clindamicina.

\section{Comentario}

El paciente fue diagnosticado de ascitis con peritonitis bacteriana espontánea (PBE) por C. tertium sin deterioro 
de la función renal. C. tertium es un clostridio aerotolerante no productor de toxinas. Crece formando colonias mates de 2-4 mm de diámetro, circulares, ligeramente irregulares, de color blanco-grisáceo. En las tinciones, se observan bacilos rectos móviles, que se tiñen de forma variable con la tinción de Gram, largos, delgados y con esporas ovales en posición terminal. Pueden ser confundidos fácilmente con bacilos gramnegativos y se pueden distinguir de las especies de Bacillus porque solamente forman esporas en condiciones anaeróbicas. Son bilis esculina positivos y fermentan la glucosa, lactosa y manitol.

Aunque en un principio se le consideró no patógeno para el ser humano, posteriormente se le ha descrito asociado a diversos cuadros infecciosos ${ }^{1-4}$; aislándose con mayor frecuencia en pacientes inmunodeprimidos (especialmente neutropénicos ${ }^{5}$ ) y alcohólicos crónicos ${ }^{6}$. Sin embargo, las PBE por esta bacteria son excepcionales; la búsqueda bibliográfica realizada en MEDLINE (1957-2005) sólo cita un caso en la literatura médica ${ }^{7}$.

Aunque el microorganismo fue sensible in vitro a betalactámicos y metronidazol, se han descrito cepas resistentes a penicilina, cefalosporinas de amplio espectro, clindamicina y metronidazol ${ }^{4,5,8,9}$; considerando como tratamientos de elección imipenem o vancomicina ${ }^{4,5,10}$.

Las PBE producidas por anaerobios son infrecuentes (apenas el 5\%, de las cuales, más de la mitad son polimicrobianas). Según algunos autores, los microorganismos anaerobios ven dificultado su crecimiento debido a que el líquido ascítico tiene una $\mathrm{pO}_{2}$ relativamente alta ${ }^{8}$. Aunque los anaerobios constituyen una etiología poco frecuente en esta entidad clínica, deberían ser considerados al establecer la terapia empírica, ya que la convencional suele ser inadecuada para estos microorganismos, y una terapia efectiva puede ser un factor fundamental para conseguir un éxito terapéutico. Especialmente es de destacar la importancia de una identificación rápida y correcta de C. tertium en el laboratorio, debido a las dificultades que se presentan con este microorganismo, fundamentalmente por su tinción de Gram variable y por su aerotolerancia.

\section{Bibliografía}

1. Henry H. An investigation of the cultural reactions of certain anaerobes found in wounds. J Pathol Bacteriol. 1917;21:344-85.

2. Lew JF, Wiedermann BL, Sneed J, Campos J, McCullough D. Aerotolerant Clostridium tertium brain abscess following a lawn dart injury. J Clin Microbiol. 1990;28:2127-9.

3. Ray P, Das A, Singh K, Bhansali A, Yadav TD. Clostridium tertium in necrotizing fasciitis and gangrene. Emerg Infect Dis 2003; 9:1347-8.

4. Gredlein CM, Silverman ML, Downey MS. Polymicrobial septic arthritis due to Clostridium species: case report and review. Clin Infect Dis. 2000;30:590-4.

5. Steyaert S, Peleman R, Vaneechoutte, De Baere T, Claeys G, Verschraegen G. Septicemia in neutropenic patients infected with Clostridium tertium resistant to cefepime and other expanded-spectrum cephalosporins. J Clin Microbiol. 1999;37:3778-9.

6. Johnson JR, Tenover FC. Clostridium tertium bacteremia in a patient with aspiration pneumonia: an elusive diagnosis. J Infect Dis. 1988;157:854-5.

7. Butler T, Pitt S. Spontaneous Bacterial Peritonitis due to Clostridium tertium. Gastroenterology. 1982;82:133-4.

8. Leegaard M, Sandven P, Gaustad P. Clostridium tertium: 3 case reports. Scand J Infect Dis. 2005;37:230-2.

9. Goldstein EJ, Citron DM, Merriam CV, Warren YA, Tyrrell KL, Fernández HT. In vitro activities of daptomycin, vancomycin, quinupristin- dalfopristin, linezolid, and five other antimicrobials against 307 gram-positive anaerobic and 31 Corynebacterium clinical isolates. Antimicrob Agents Chemother. 2003;47:337-41.

10. Tappe D, Dirks J, Muller R, Brederlau J, Abele-Horn M, Suerbaum S, et al. Fatal Clostridium tertium septicemia in a nonneutropenic patient. J Infect. 2005;50:76-80. 